\title{
We Need to Review the Medical Care Model Based on Emergency Situations
}

\author{
Isabel DeFátima Alvim Braga ${ }^{1 *}$, Laila Zelkcovicz Ertler ${ }^{2}$, William Waissman ${ }^{3}$ \\ and Bruno DeAvilla Da Fonsecae Silva ${ }^{4}$ \\ ${ }^{1}$ Physician, lawyer and Master in collective health, Brazil
}

ISSN: 2639-0531

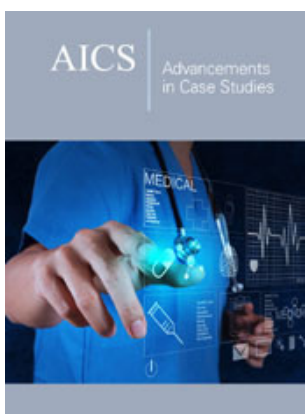

*Corresponding author: Isabel de Fátima Alvim Braga, Physician, lawyer and Master in collective health, Oswaldo Cruz Foundation-Human Resources Directory, Brazil

Submission: 睯 March 11, 2019

Published: 址 March 20, 2019

Volume 1 - Issue 5

How to cite this article: Isabel D A B, Laila Z E, William W, Bruno D D F S. We Need to Review the Medical Care Model Based on Emergency Situations. Adv Case Stud.1(5) AICS.000524.2019.

DOI: 10.31031/AICS.2019.01.000524

Copyright@ Isabel de Fátima Alvim Braga, This article is distributed under the terms of the Creative Commons Attribution 4.0 International License, which permits unrestricted use and redistribution provided that the original author and source are credited.

\author{
${ }^{2}$ Neurosurgeon and Professor, Vice coordinator of Medicine School of Rio de Janeiro Federal \\ University, Brazil \\ ${ }^{3}$ Physician and $\mathrm{PhD}$ in collective health, Brazil \\ ${ }^{4}$ Engineer, Telecommunications engineering of Federal Fluminense University, Brazil
}

\section{Editorial}

Medical urgency is defined as the unforeseen occurrence of a health problem with or without a potential risk of death. Medical emergency is the condition that implies an imminent risk of death or intense suffering. In both cases, need for medical care is immediate [1]. Efficient care in the above situations in the emergency room is of paramount importance for life and death situations. Nevertheless, problems in these establishments generate disorders in various spheres of human well-being. Incidence of errors in situations requiring fast thinking is highly dependent on the experience of the emergency physician [2], but the analysis of this professional in this type of situation lacks the history of the patient and information that may be essential for the correct diagnosis [3]. Emergency situations, due to their very nature, have been presented with a wide range of errors and have been linked to a large contingent of cases due to medical error, both in the civil and criminal spheres [4]. It is allied to the fact that the search for these places of care is not always done by individuals in a condition of emergency and in fact urgent, with a large contingent of situations in these places that could be solved in an outpatient way.

Emergency room care has limited time, unpredictability and lack of continuity of the patient-physician relationship [5]. The professional's insecurity regarding the possibility of ethical-professional processes due to the lack of follow-up and to the doubt generates, in cases of less complexity, an excessive use of antibiotics, exams and interventions in the patient, contributing to the hyper diagnosis and increase of adverse effects of medicines. It is well known that the medicines have light and dark sides [6], which is why their use should be made with parsimony by health professionals. Incorrect administration of antimicrobial substances may compromise the patient's clinical response, reduce the financial effectiveness of their use and contribute to the emergence of multi-drug resistant microorganisms [7]. Antibiotic resistance through the indiscriminate use of these drugs has been identified as a global public health problem with serious consequences for the health of the global population. It should also be asked if the high cost of these practices has been accompanied by an improvement in the quality of these services.

The search for emergency services for injuries that could be avoided with simple preventive measures is not an exclusivity of the medical practice and per pass the dental practice. Dental cleaning, fluoride use, and health education are examples of good practices that prevent more serious oral disorders [8]. Studies have shown that the classification of risk made by nursing professionals in general emergency rooms improves the effectiveness of care, but there is difficulty in following these patients [9]. Although it contributes to the better organization of the service and quick care prioritizing the most serious situations, the risk classification does not totally prevent the patient from generating costs for the health 
systems, since it does not contribute to reducing the number of patients who look for attending at emergency room.

Building health more faithful to the primum non Nocera principle requires a paradigm shift from the axis of the hyper interventionist model to the health promotion model focused on primary preventive care coined by Lavelle and Clark [10]. Adequate diet, physical activity, accident prevention, health education, vaccination and other preventive measures should be the pillars of the health model worldwide. The aforementioned measures have low relative cost and effectiveness in providing quality of life. However, incorrect interpretations of epidemiological data and rumors spread in social networks have repeatedly contributed to antagonistic movements to these good practices, with the propagation of anti-vaccine movements and miraculous diets with nutrient precariousness.

Despite the undeniable importance of outpatient services in reducing attendance and costs with emergency care, it is known that they still do not avoid all emergency health problems. In obstetrics, for example, a well-done prenatal care with accurate assessment of maternal and fetal risk consistently reduces the morbidity and mortality of these groups, but not completely, due to the unpredictability of some adverse outcomes, which even resists good practices [11]. Is in this context that science and good practices in research are fundamental for the construction of collective health. Nonetheless, scientific research in this field still has gaps to be filled. Although an immeasurable number of studies are published each year, proportionally few are those that deal with analysis of emergency services. This is justified by the difficulty of analyzing interventions in this sector, since there is a lack of data filling in medical records and a very high complexity and variety of analysis possibilities. Thus, the future of medicine seems to be focused on the development of an increase in the processing capacity of an immense volume of data that has been generated in research [12] and not on the irresponsible increase in the costs of emergency care.
Thus, the current model of excesses in emergency care urgently needs to be reinterpreted by patient and health care professionals based on evidences and thus enable the system to provide good health at reasonable costs that do not implode it.

\section{References}

1. Conselho Regional de Medicina do Estado de São Paulo (CREMESP) (2000) Manual de diretoria clínica. Cremesp, São Paulo, Brazil, p. 15.

2. Kahneman D, Egan P (2013) Thinking, fast and slow. Farrar Straus Giroux.

3. Braga IF, Ertler LZ, Aquino RM, Da Fonsecae Silva BA, Pereira RB, et al (2018) Responsabilização penal do médico no Tribunal de Justiça do Estado de São Paulo. Einstein (São Paulo) 16(1): eA04060.

4. Ertler LZ, Braga IFA, Pereira RBM, Aquino RM, Silva BAF (2018) Erro médico na esfera penal no tribunal de justiça do rio grande do sul. Rev AMRIGS 62(1).

5. Braga IFA, Ertler LZ, Garbin HBR (2017) Understanding of the court of justice of pará on medical error in the criminal sphere. ABCS Health Science 42(3): 156-160.

6. Fumihiko $H$ (2017) Consideration of the light and dark sides of medicines: The thalidomide example. Adv Case Stud 1(1).

7. Mota LM, Vilar FC, Dias LBA, Nunes TF, Moriguti JC et al. (2010) Uso racional de antimicrobianos. Medicina (Ribeirão Preto) 43(2): 164-72.

8. Almeida GCM, Ferreira MAF (2008) Saudi buccal no context to do Program Saudi da Familia: practices de prevenção orientates ao individua e ao collective; Oral health in the context of the family health program: preventive practice star getting individual and public health. Cad Saúde Pública Rio De Janeiro 24(9): 2131-2140.

9. Nascimento, Eliane Regina Pereira, Hilsendeger, Barbara Rosso, Neth, et al. (2011) Risk rating in the emergency department: Assessment of the nursing team. Rev Enferm UERJ 19(1): 84-88.

10. Leavell H, Clark E (1958) Preventive medicine for the doctor in his community an epidemiologic approach. McGraw-Hill.

11. Isabel De FAB, Renata BMP, Leavell ZE (2018) Civil liability of obstetrician at the court of justice of the state of rio de janeiro. Adv Case Stud. 1(2).

12. Martins TG, Costa AL, Martins TG (2018) Big Data use in medical research. Einstein (São Paulo) 16(3): eED4087. 